\title{
BMJ Open Assessment of earthquake casualties and comparison of accuracy of five injury triage methods: evidence from a retrospective study
}

\author{
Yang Peng, ${ }^{1,2}$ Hai Hu (D) ${ }^{2,3}$
}

To cite: Peng Y, Hu H. Assessment of earthquake casualties and comparison of accuracy of five injury triage methods: evidence from a retrospective study. BMJ Open 2021;11:e051802. doi:10.1136/ bmjopen-2021-051802

- Prepublication history for this paper is available online. To view these files, please visit the journal online (http://dx.doi. org/10.1136/bmjopen-2021051802).

Received 31 March 2021 Accepted 21 September 2021

D) Check for updates

(C) Author(s) (or their employer(s)) 2021. Re-use permitted under CC BY-NC. No commercial re-use. See rights and permissions. Published by BMJ.

${ }^{1}$ Center of Excellence for International Cooperation in Medicine, Sichuan University West China Hospital, Chengdu, Sichuan, China

${ }^{2}$ China International Emergency Medical Team (Type 3),

Chengdu, Sichuan, China

${ }^{3}$ Emergency management office of West China Hospital, Sichuan University West China Hospital, Chengdu, Sichuan, China

Correspondence to

Dr Hai Hu; 317626915@qq.com

\section{ABSTRACT}

Objective The use of an injury triage method among earthquake injury patients can facilitate the reasonable allocation of resources, but the various existing injury triage methods need further confirmation. This study aims to assess the accuracy of several injury triage methods, namely, the Simple Triage and Rapid Treatment (START) technique; CareFlight Injury Triage (CareFlight); Rapid Emergency Medicine Score (REMS); Triage Revised Trauma Score (T-RTS) and Triage Early Warning Score (TEWS), based on their effects on earthquake injury patients. Design Data in the Huaxi Earthquake Casualty Database were analysed retrospectively.

Setting This study was conducted in China.

Participants Data on 29523 earthquake casualties were separately evaluated using the START technique, CareFlight, REMS, T-RTS and TEWS, with these being the five types of injury triage studied.

Primary outcome measure The receiver operating characteristic (ROC) curves for the five injury triages were calculated based on hospital deaths, injury severity scores greater than 15 points, and whether casualties stayed in the intensive care unit.

Results The ROC curve areas of the START technique, CareFlight, REMS, T-RTS and TEWS were 0.750, 0.737, $0.835,0.736$ and 0.797 , respectively. Among the five injury triages, the most accurate in predicting hospital deaths was REMS, with an average area under the curve (AUC) of 0.835 , with this due to the inclusion of more evaluation indicators.

Conclusion All methods had an effect on the triage of earthquake mass casualties. Among them, the REMS injury triage method had the largest AUC of the five triage methods. Except for REMS, no obvious difference was found in the effect of the other four injury triage methods.

\section{INTRODUCTION}

Earthquake injuries, involving a large number of casualties and caused by sudden natural disasters, are characterised by sudden, shortterm injuries, difficulties in rescuing casualties and the high risk of death of those injured. ${ }^{1}$ When a destructive earthquake occurs, many casualties occur at the earthquake site, which often lacks adequate medical resources. ${ }^{2}$ To save the lives of as many casualties as possible,
Strengths and limitations of this study

- This is the first study to simultaneously compare these five injury triage methods.

- This database, which includes casualties from several devastating earthquakes, is both huge and representative.

- This study adopted several outcome measurement indicators to compare effectiveness from different aspects.

- This study considered the effectiveness of injury triage methods but not their convenience.

rational use needs to be made of the limited medical resources at the site, classifying and processing the mass of casualties, ${ }^{3}$ and determining which casualties with life-threatening injuries should be given priority treatment. ${ }^{4}$ It is also necessary to identify which casualties can have treatment delayed, as well as those whose lives, even if immediate treatment were available, would be difficult to save. Thus, their treatment would have to be suspended in order to save the casualties considered the most valuable, with the maximum survival rate and minimum level of disability. ${ }^{5}$ With such a large number of injured people with different conditions, the process of correct injury triage within a short period of time is particularly important, ${ }^{6}$ especially for those assessed as critical (injuries classified as red) and more serious (injuries classified as yellow). A good triage of injuries should simultaneously meet three conditions: (1) clinical operability; (2) a simple and fast scoring method and (3) highly accurate predictions. ${ }^{7}$

The purpose of using triage methods is to enable the healthcare provider to assess patients' severity of injury or illness, assign priorities and to transfer each patient to the appropriate place for treatment. Patients with severe injury need to be separated from moderate and mild injuries. In a retrospective 
analysis one may consider severely injured patient (red) as the one who dies or needs to be admitted to intensive care unit (ICU) or has injury severity score (ISS) $>15$. A patient with moderate injury (yellow) may be a patient who needs hospitalisation but has ISS $<15$ and does not need ICU care. The remaining may be considered as patients with mild injuries (green).

Several injury triage methods are available, such as the Simple Triage and Rapid Treatment (START) technique; CareFlight Injury Triage (CareFlight); Rapid Emergency Medicine Score (REMS); Triage Revised Trauma Score (T-RTS) and Triage Early Warning Score (TEWS). The earliest and most widely used injury triage method is the START technique which evaluates patients by their degree of action (walking), breathing, blood flow perfusion, and consciousness status, ${ }^{8}$ classifying patients into red tags (immediate treatment), yellow tags (delayed treatment), green tags (minor injuries) and black tags (not expected to be saved). ${ }^{9}$

CareFlight is a simplified procedure, similar to the START technique, which divides patients into four categories, namely, red, yellow, green and black tags, mainly through the assessment of movement (walking), consciousness, breathing and blood flow perfusion. ${ }^{10}$ The REMS method is a score based on the casualty's age (year); mean arterial pressure $(\mathrm{mm} \mathrm{Hg})$; breathing rate (second/min); heart rate (second/point); $\mathrm{SPO}_{2}(\%)$ and Glasgow Coma Scale (GCS) (score). ${ }^{11}$ The higher the score, the higher the patient's criticality, with the severity of the patient's condition evaluated according to the patient's score. ${ }^{12}$ The scoring method, T-RTS, comprises three indicators, namely, systolic blood pressure, breathing rate and the GCS score; the lower the score, the more serious the injury. ${ }^{13}$ Similar to the two previous triage methods, TEWS uses a scoring method which, in this method, comprises seven indicators, that is, mobility, breathing rate, heart rate, systolic blood pressure, body temperature, state of consciousness and level of trauma; the higher the score, the more severe the injury. ${ }^{14}$

Although many injury triage methods are available, only extremely limited performance comparison has been undertaken of these methods. ${ }^{15}$ Difficulties experienced in the prospective study of seismic injury triage include the sudden and non-repeatable nature of earthquakes, practical problems of random grouping, ethical issues, logistics and cost. ${ }^{16}$ Thus, simulation research and postassessment studies, rather than prospective trials, provide most of the available evidence. In addition, researchers have used data on non-mass casualties, such as estimated relative risk injury registry data, to study ways in which to evaluate the results of mass casualty triage systems. The key to this registry-based research is to link initial information about out-of-hospital patients (eg, their mental state and the vital signs used for diversion distribution) to the clinical significance of an enormous number of trauma patients.

To date, very few studies have been reported in the literature on the use of large amounts of seismic injury data to evaluate triage methods for detecting injuries. In the current study, we have sought to compare the performance of five injury triage methods. We have applied these methods to the Huaxi Earthquake Casualty Database, comparing the calculated patient triage priority with the results recorded for the patient. Our hypothesis is that some injury triage methods are able to predict the main clinical results more accurately than others.

\section{METHODS}

\section{Research design}

The current study used existing patient characteristics and results from the Huaxi Earthquake Casualty Database to compare the performance of five injury triage methods. Each method was retrospectively used for every patient in the database to obtain the specified triage level or scoring value, and then compared with the actual recorded results of each patient (hospital deaths, admission to the ICU or ISSs higher than 15 points). ${ }^{17-19} \mathrm{~A}$ direct comparison was then made of the performance for each method.

\section{Selection of participants}

Data on patient populations were derived from a database of earthquake casualties from previous devastating earthquakes in western China over the decade from 2008 to 2018. These data were collected from out-of-hospital and emergency department (ED) information, as well as inpatient information and discharge information.

\section{Data collection}

For this study, a patient with a valid record of age and complete result reported in both ED and final discharge would be included. However, those without valid records of prehospital vital signs or other essential information for calculating GCS and ISS were excluded. This study also classified patients using the following tags: red (immediate treatment), yellow (delayed treatment), green (minor injuries) and black (not expected to be saved). ${ }^{9}$ The mortality, need for intensive care unit admission and severe injury (ISS >15) were recorded as binary nominal data.

\section{Outcome determination}

The main result used was the hospital mortality rate, as recorded in the database. Comparisons were undertaken between the mortality rate, the initial triage allocation, the receiver operating characteristic (ROC), as well as the area under the curve (AUC). Two secondary results were used: first, whether the patient stayed in the ICU, with this defined as the patient entering the ICU during hospitalisation. This binary result was compared with the ROC and AUC, as well as with the initial triage assignment. The other secondary result was whether the patient's ISS was higher than 15 points, with an ISS higher than 15 points being for critically injured patients. This binary result was compared with the ROC and AUC, as well as with the initial triage assignment. 


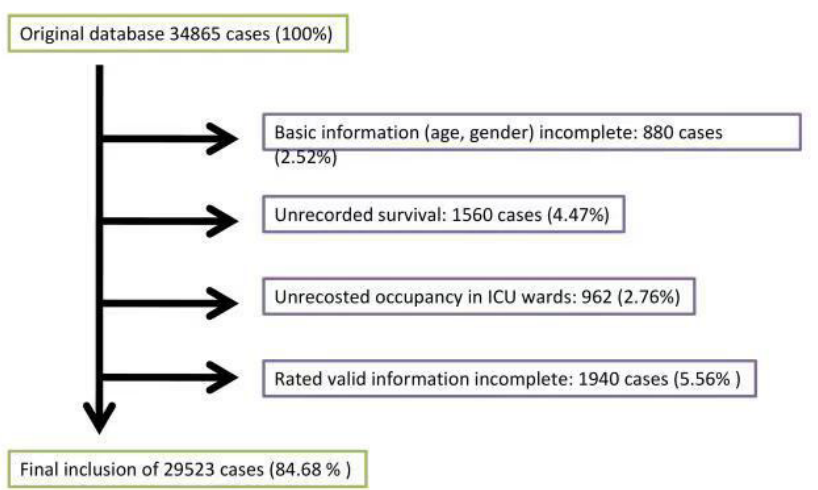

Figure 1 Details of patients included in the study. ICU, intensive care unit.

\section{Statistical analysis}

The statistical analysis was undertaken with IBM SPSS Statistics (SPSS) V.20.0 and MedCalc statistical software V.18.2.1 (MedCalc Software, Ostend, Belgium). The continuous variables shown were based on means $( \pm)$, SD or medians $(25 \%$ quartile, $75 \%$ quartile), as appropriate. Other variables were shown according to composition ratios (\%). This study used the Student's t-test or Mann-Whitney U test to show comparisons between continuous variables. Similarly, the $\chi^{2}$ test or Fisher's exact test were undertaken to show comparisons between categorical variables.

To assess the abilities of the five injury triage methods to predict mortality, ROC curve analyses were conducted. The triage performance of these scoring systems to discriminate between outcomes was evaluated by calculating the AUC of ROC and its 95\% CI. An AUC >0.75 was considered to have a suitable clinical value, while an AUC >0.97 was viewed as a high clinical value. The AUCs were compared by conducting Delong's test.

\section{Patient and public involvement}

No patient was involved in this study.

\section{RESULTS}

After excluding 5342 patients with missing records (figure 1), 29523 injured persons, in total, were recorded in the Huaxi Earthquake Casualty Database.

The analysis revealed that most survivors $(51.12 \%)$ and most of those who died $(56.68 \%$ to a total number of 217 persons died) were female, while the rest were male. The analysis of the five triage methods indicated significant differences between them. The basic characteristics are summarised in table 1 .

Taking hospital death as the evaluation criterion, the ROC curve of each injury triage method is shown in figure 2.

The performance of the various triage methods, namely, the START technique, CareFlight, REMS, T-RTS and TEWS, were analysed in terms of in-hospital deaths, ISSs and ICU admissions. The obtained values were calculated on the basis of the AUC at a 95\% CI. Table 2 presents the AUC of the five injury triage methods 2.
Table 1 Summary of the characteristics of earthquake survivors and non-survivors

\begin{tabular}{|c|c|c|c|}
\hline Variable & $\begin{array}{l}\text { Survivors } \\
N=29306\end{array}$ & $\begin{array}{l}\text { Non-survivors } \\
\mathrm{N}=217\end{array}$ & $P$ value \\
\hline Male (number) & $14326(48.88 \%)$ & $94(43.32 \%)$ & 0.102 \\
\hline Female (number) & 14980 (51.12\%) & 123 (56.68\%) & \\
\hline Age (years) & $50.46 \pm 17.94$ & $61.22 \pm 19.70$ & $<0.01^{*}$ \\
\hline \multicolumn{4}{|l|}{ Vital signs } \\
\hline Temperature $\left({ }^{\circ} \mathrm{C}\right)$ & $36.75 \pm 0.45$ & $36.89 \pm 0.77$ & 0.130 \\
\hline $\mathrm{RR}(/ \mathrm{min})$ & $19(18,20)$ & $21(20,24)$ & $<0.01^{*}$ \\
\hline $\mathrm{PR}$ (/min) & $80(76,85)$ & $90(78,109)$ & $<0.01^{*}$ \\
\hline $\mathrm{SBP}(\mathrm{mm} \mathrm{Hg})$ & $122.7 \pm 17.4$ & $115.1 \pm 27.2$ & $<0.01^{*}$ \\
\hline \multicolumn{4}{|l|}{ Consciousness } \\
\hline GCS & $15(15,15)$ & $14(7,15)$ & $<0.01^{*}$ \\
\hline A & $28020(95.61 \%)$ & $104(47.93 \%)$ & $<0.01^{*}$ \\
\hline $\mathrm{V}, \mathrm{P}, \mathrm{U}$ & 1286 (4.39\%) & $113(52.07 \%)$ & \\
\hline ISS & $9(1,13)$ & $9(4,18)$ & $<0.01^{*}$ \\
\hline \multicolumn{4}{|l|}{ Triage tools } \\
\hline \multicolumn{4}{|l|}{ START } \\
\hline Green (number) & 102 & 1 & $<0.01^{*}$ \\
\hline Yellow (number) & 27842 & 97 & \\
\hline Red (number) & 1362 & 119 & \\
\hline Black (number) & 0 & 0 & \\
\hline \multicolumn{4}{|l|}{ CareFlight } \\
\hline Green (number) & 102 & 1 & $<0.01^{*}$ \\
\hline Yellow (number) & 27917 & 103 & \\
\hline Red (number) & 1287 & 113 & \\
\hline Black (number) & 0 & 0 & \\
\hline REMS & $2(0,5)$ & $7(5,9)$ & $<0.01^{*}$ \\
\hline T-RTS & $12(12,12)$ & $11(9,12)$ & $<0.01^{*}$ \\
\hline TEWS & $4(4,5)$ & $6(5,8)$ & $<0.01^{*}$ \\
\hline
\end{tabular}

${ }^{*} \mathrm{P}<0.05$.

A, alert; GCS, Glasgow Coma Scale score; HR, heart rate; ISS, injury severity score; P, pain; PR, pulse rate; REMS, Rapid Emergency Medicine Score; RR, respiratory rate; SBP, systolic blood pressure; START, Simple Triage and Rapid Treatment; STM, Sacco Triage Method; TEWS, Triage Early Warning Score; T-RTS, Triage Revised Trauma Score; U, unresponsive; V, verbal.

Based on a participant's stay in the ICU being used as an evaluation criterion, the ROC curve of each injury triage method is shown in figure 3 .

A pairwise comparison was undertaken between the five injury triage methods by Delong's method. The AUC values were calculated for each pair, along with a comparison at $95 \% \mathrm{CI}$, and an analysis of $\mathrm{z}$-statistics and $\mathrm{p}$ values. The $p$ value comparison indicated that a significant relationship was found between each pair. The pairwise values of the five injury triage methods are shown in table 3 .

Based on ISS >15 as the evaluation criterion, the ROC curve of each injury triage method is shown in figure 4, with the curve area of START, CareFlight and REMS injury triage shown in table 2 . The five injury triage methods are not higher than the value of $\mathrm{ISS}=15$. 


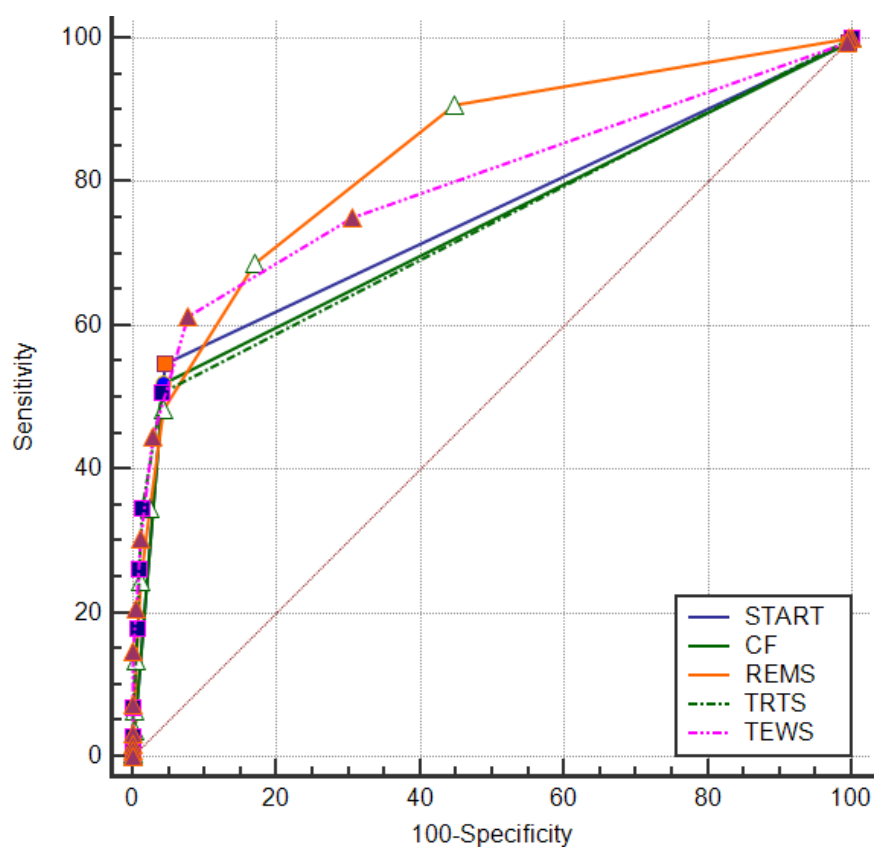

Figure 2 Receiver operating characteristic curves for values of each injury triage method based on hospital deaths. CF, CareFlight tool; REMS, Rapid Emergency Medicine Score; START, Simple Triage and Rapid Treatment; TEWS, Triage Early Warning Score; T-RTS, Triage Revised Trauma Score.

\section{DISCUSSION}

Over the past few decades, the number of mass casualty incidents has risen. ${ }^{20}$ When a mass casualty event occurs, normally a disparity occurs between the number of victims and the medical resources available. ${ }^{21}$ In such cases, triage is essential to ensure that sufficient medical

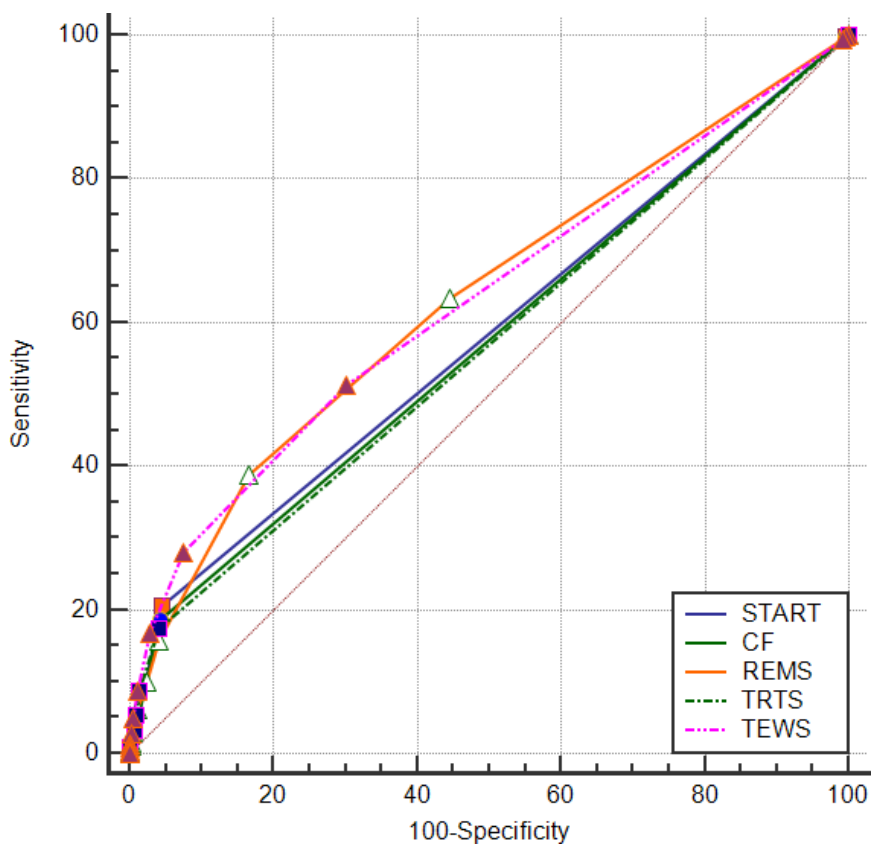

Figure 3 Values of each injury triage method based on an intensive care unit stay. CF, CareFlight tool; REMS, Rapid Emergency Medicine Score; START, Simple Triage and Rapid Treatment; TEWS, Triage Early Warning Score; T-RTS, Triage Revised Trauma Score.

resources reach the maximum possible number of casualties. The goal of triage is to offer the right treatment to each patient at the right time and in the right place.

Earthquakes are a natural hazard that results in a large number of deaths. ${ }^{22}$ The conditions triggered by an earthquake that affect the likelihood and degree of damage

Table 2 Summary of injury triage methods in predicting earthquake victim outcomes

\begin{tabular}{|c|c|c|c|c|c|c|}
\hline Outcome & Tools & AUC & $95 \% \mathrm{Cl}$ & Cut-off & Sen. (\%) & Spe. (\%) \\
\hline \multicolumn{7}{|c|}{ In-hospital death } \\
\hline & START & 0.750 & 0.745 to 0.755 & Red & 54.8 & 95.4 \\
\hline & REMS & 0.835 & 0.831 to 0.840 & 4 & 82.0 & 76.9 \\
\hline & T-RTS & 0.736 & 0.731 to 0.741 & 11 & 50.7 & 95.8 \\
\hline & START & 0.581 & 0.576 to 0.587 & Red & 20.6 & 95.5 \\
\hline & CareFlight & 0.573 & 0.568 to 0.579 & Red & 18.8 & 95.7 \\
\hline & REMS & 0.634 & 0.628 to 0.639 & 4 & 56.0 & 67.3 \\
\hline & T-RTS & 0.567 & 0.561 to 0.572 & 11 & 17.4 & 95.8 \\
\hline & CareFlight & 0.515 & 0.509 to 0.521 & Red & 7.0 & 95.8 \\
\hline & REMS & 0.553 & 0.548 to 0.559 & 4 & 42.6 & 69.0 \\
\hline & T-RTS & 0.510 & 0.504 to 0.516 & 11 & 6.2 & 95.8 \\
\hline & TEWS & 0.532 & 0.526 to 0.538 & 6 & 35.5 & 70.3 \\
\hline
\end{tabular}

AUC, area under the curve of the receiver operating characteristic; CareFlight, CareFlight Injury Triage; ICU, intensive care unit; ISS, injury severity score; REMS, Rapid Emergency Medicine Score; Sen., sensitivity; Spe., specificity; START, Simple Triage and Rapid Treatment; TEWS, Triage Early Warning Score; T-RTS, Triage Revised Trauma Score. 
Table 3 Summary of pairwise comparisons of the AUC of injury triage tools used in predicting in-hospital mortality of earthquake victims

\begin{tabular}{lcccc}
\hline Pairwise models & DAUC & $\mathbf{9 5 \%} \mathbf{C l}$ & z-statistic & P value \\
\hline START CF & 0.0125 & 0.00162 to 0.0234 & 2.251 & $0.024^{*}$ \\
START REMS & 0.0857 & 0.0582 to 0.113 & 6.109 & $<0.001^{*}$ \\
START T-RTS & 0.0133 & -0.00678 to 0.0334 & 1.299 & 0.194 \\
START TEWS & 0.0474 & 0.0153 to 0.0795 & 2.893 & $0.004^{*}$ \\
CF $\sim$ REMS & 0.0983 & 0.0699 to 0.127 & 6.794 & $<0.001^{*}$ \\
CF $\sim$ T-RTS & 0.0008 & -0.0222 to 0.0238 & 0.069 & 0.945 \\
CF $\sim$ TEWS & 0.0599 & 0.0262 to 0.0935 & 3.489 & $<0.001^{*}$ \\
REMS T-RTS & 0.0991 & 0.0697 to 0.128 & 6.613 & $<0.001^{*}$ \\
REMS TEWS & 0.0384 & 0.00581 to 0.0709 & 2.310 & $0.021^{*}$ \\
\hline T-RTS TEWS & 0.0607 & 0.0316 to 0.0898 & 4.083 & $<0.001^{*}$ \\
\hline
\end{tabular}

${ }^{*} \mathrm{P}<0.05$.

$\triangle A U C$, difference between the areas under the curve; CF, CareFlight tool; REMS, Rapid Emergency Medicine Score; START, Simple Triage and Rapid Treatment; TEWS, Triage Early Warning Score; T-RTS, Triage-Revised Trauma Score.

are referred to as 'earthquake population vulnerability'. With the global population's continued growth and large-scale urbanisation, earthquakes will pose a greater threat to human safety. ${ }^{8}$ While our level of technology does not allow us to accurately predict an earthquake, earthquakes can be researched from two perspectives to minimise, as much as possible, the number of people killed or injured. ${ }^{23}$ First, earthquake disaster susceptibility assessments should be completed well in advance of an earthquake, ${ }^{24}$ with disaster avoidance and mitigation systems improved in areas where population vulnerability

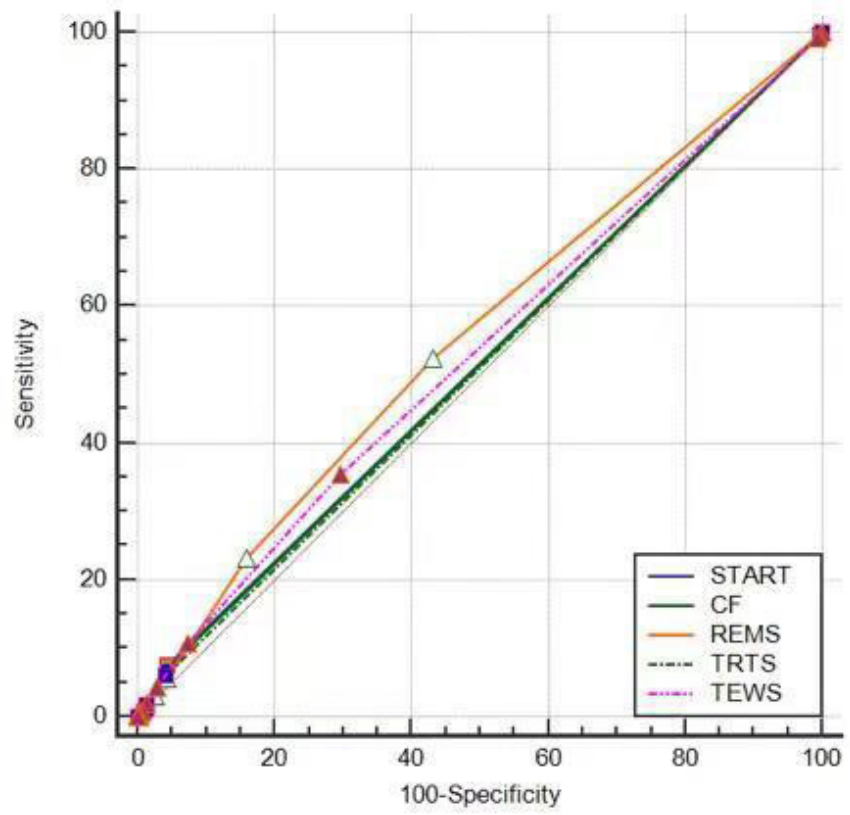

Figure 4 Values of each injury triage method according to higher ISS value. CF, CareFlight Injury Triage; REMS, Rapid Emergency Medicine Score; START, Simple Triage and Rapid Treatment; TEWS, Triage Early Warning Score; T-RTS, Triage Revised Trauma Score. is relatively high. ${ }^{25}$ Second, the number of casualties must be projected immediately after the earthquake, and appropriate rescue steps should be deployed based on the estimated results of carrying these out effectively. ${ }^{26}$ Only an effective triage method can reduce mortality when using limited resources and having little time. ${ }^{14}$

Many methods of injury triage, such as the START technique, CareFlight, REMS, T-RTS and TEWS, are available worldwide. The obtained value of the AUC is 0.75 (at 95\% CI 0.745 to 0.755 ) for in-hospital deaths, with these values being 0.581 (at $95 \%$ CI 0.576 to 0.587 ) and 0.517 (at $95 \%$ CI 0.511 to 0.523 ) for ICU admissions and the ISS $>15$ condition. In the study conducted by Cross and Cicero ${ }^{9}$ on 1816982 US casualties based on their deaths, the recorded value of the AUC was $0.846(95 \%$ CI 0.843 to 0.849$)$. He also reported obtaining the AUC value of 0.852 (95\% CI 0.850 to 0.855 ) from the CareFlight method.

In the study by Imhoff $e t a l,{ }^{11}$ the author reported that the AUC value reached 0.91 using the REMS injury triage method. In the initial assessment of trauma patients, the simple addition of T-RTS, or the Revised Trauma Score's three indicator scores, has also been considered by researchers for use as an injury triage method for mass casualties. In a study of 150 trauma patients, MacLeod et $a l^{15}$ found that the ROC curve of T-RTS had an area of 0.869. In Gottschalk et $a l \mathrm{~s}^{27}$ study, the advantage of TEWS was found to be that, in prehospital and emergency room settings, parameters that were easily measured by staff with basic training were converted to equally easy and interpretable triage scores. By using these injury triage methods, healthcare providers would similarly be able to classify patients, making communication between medical staff more transparent, enabling the more appropriate transfer of patients. ${ }^{28}$ However, no evidence has previously been available to support which method is the most appropriate for the treatment of mass casualties. 
The current study evaluates the effect of injury triage using these five methods by retrospectively analysing data from the Huaxi Earthquake Casualty Database, and providing evidence to support the effectiveness of each triage method.

Our study found that all five methods were of value, based on the number of hospital deaths. With the START technique, the AUC value for predicting in-hospital deaths in earthquake batch trauma patients was found to be 0.75 , which is acceptable for performance. The main limitation of the START technique appeared to be that only four indicators were required. More injury triage indicators could better distinguish between patient urgency and clinical needs. However, this increase in differentiation would come at the expense of increased complexity. Triage methods with more evaluation indicators (eg, REMS and TEWS) were found to be better than the START technique. The CareFlight method predicted hospital deaths with an average AUC (AAUC) of 0.737 , lower than for the START technique, with its selected metrics consistent with the START technique but more simplified. Bazyar et al $\mathrm{s}^{14}$ study suggested that the START technique's assessment time in the field is about $30 \mathrm{~s}-60 \mathrm{~s}$, while CareFlight takes only $15 \mathrm{~s}$. To some extent, this reduces accuracy, but it can still be considered in cases with large numbers of injuries and scarce medical resources. In relation to predicting hospital deaths using the five injury triage methods, REMS has the highest value with an AAUC of 0.835 , with the high accuracy of its predictions mainly due to the inclusion of more evaluation indicators. However, the REMS indicators include data on blood pressure and oxygen saturation, thus increasing the demand for medical equipment in the field. Sufficient numbers of these devices would be required to calculate REMS, with this also being the limitation of REMS application in earthquake sites. ${ }^{11}$ With an AAUC of 0.736, the accuracy of predictions by T-RTS is not ideal, with blood pressure also needing to be measured. Therefore, its field application value is not as good as that of CareFlight. With an AAUC of 0.797 which is better than for the START technique, TEWS also requires systolic pressure and body temperature measurement, thus needing these measuring devices to be available in the field.

In addition, our study found that three of the five injury triage methods had an AUC below 0.75, based on whether a patient had an ISS $>15$ or required an ICU stay. These two secondary results are important criteria to alert medical personnel on the spot to the needs of patients. However, no strong evidence is available to show which injury triage method is superior in these aspects so this needs to be explored in future studies. The analysis revealed that START, CareFlight and T-RTS showed poor sensitivity but high specificity for admission to ICU and ISS $>15(>95 \%$, table 2$)$, which indicated that those who were identified positive by these three triage methods were more likely to be admitted to the ICU or have severe injuries. However, negative could not be considered as mild. Therefore, we suggested that more medical resources were beneficial for positive patients; while further evaluation was needed for negative patients when resources were sufficient.

\section{LIMITATIONS}

This study only considered the effectiveness of injury triage methods. However, in real-world cases, the convenience of injury triage is also very important. Owing to missing data, the available records were not usable in relation to convenience. Although statistical results were provided using ROC comparisons, the size of the clinically relevant differences remained unclear. Any clinical differences between the injury triage methods may be further blurred when people consider the inconsistency with which triage methods are applied by first responders who have limited disaster experience. In earthquake rescues, it is not only the performance of these methods that should be considered, but more should be learnt about the comparative advantages and disadvantages of each injury triage method.

Owing to missing data of 'deaths at the scene or on arrival', we mainly analysed the in-hospital deaths.

Along with the application of $\mathrm{SpO}_{2}$ measurement, REMS, T-RTS and TEWS can also be used prehospital, ${ }^{29-31}$ which could be further discussed.

In addition, we did not analyse the consuming time of different triage methods because of lacking essential data.

Because of the lack of actual data, we were not able to compare predicted and actual cases by different triage methods.

\section{CONCLUSION}

The structured method of assessing priorities for care based on the seriousness of each patient's condition is known as emergency triage. The primary goal of triage is to ensure that patients receive the most suitable level of treatment based on their health condition, with a particular emphasis on patients who are at a higher risk of dying. The START technique, CareFlight, REMS, T-RTS and TEWS are five injury triage methods used to help assess patients at risk of dying in hospital and, thus, they support the allocation of reasonable resources, with the REMS method found to be superior in this aspect to the other four methods. The REMS method demonstrated that it had the highest value in predicting hospital deaths among the five injury triage methods. It had an AAUC of 0.835 , with the high accuracy of its predictions mainly due to the inclusion of more evaluation indicators. However, in assessing patients' ISSs or whether they needed to be admitted to the ICU, none of the five injury triage methods was found to be ideal, with further research needed.

Contributors YP and HH participated in the study design, data analysis and interpretation. YP drafted the manuscript. $\mathrm{HH}$ is the guarantor and critically revised the manuscript. Both authors read and approved the final manuscript. 
Funding This work was financially supported by the Strategic Priority Research Programme of the Chinese Academy of Science (XDA23090502) and Science and Technology Department of Sichuan Province (21KJPX0207).

\section{Competing interests None declared.}

Patient and public involvement Patients and/or the public were not involved in the design, or conduct, or reporting, or dissemination plans of this research.

\section{Patient consent for publication Not applicable.}

Ethics approval The study was approved by the Institutional Review Board (IRB) of the West China Hospital in Sichuan University, China. The data were anonymised before being accessed by the authors for the purpose of this study.

Provenance and peer review Not commissioned; externally peer reviewed. Data availability statement Data are available upon reasonable request.

Open access This is an open access article distributed in accordance with the Creative Commons Attribution Non Commercial (CC BY-NC 4.0) license, which permits others to distribute, remix, adapt, build upon this work non-commercially, and license their derivative works on different terms, provided the original work is properly cited, appropriate credit is given, any changes made indicated, and the use is non-commercial. See: http://creativecommons.org/licenses/by-nc/4.0/.

ORCID iD

Hai Hu http://orcid.org/0000-0003-3256-6941

\section{REFERENCES}

1 Jie S, Sissy BY, Hai H. The effect of different emergency evacuation and misdiagnosis processes in Lushan and Wenchuan earthquakes on the time of emergency stay for earthquake casualties. Chinese $J$ Evidence-Based Med 2013;13:637-40.

2 Gao X, Leng Y, Guo Y, et al. Association between earthquake experience and depression 37 years after the Tangshan earthquake: a cross-sectional study. BMJ Open 2019;9:e026110.

3 Tsukinoki R, Murakami Y, Kawado M, et al. Comparison of standardised mortality ratios for renal failure before and after the 2011 great East Japan earthquake and tsunami: an analysis of national vital statistics. BMJ Open 2018;8:e023435.

4 Romero Pareja R, Castro Delgado R, Turégano Fuentes F, et al. Prehospital triage for mass casualty incidents using the META method for early surgical assessment: retrospective validation of a hospital trauma registry. Eur J Trauma Emerg Surg 2020;46:425-33.

5 Bruno L. Human casualties earthquakes. New York, USA: Springer Science+Business Media B.V, 2011.

6 Li Xiaohui HH, Yongli G, et al. 4.20 analysis of injuries and injuries in 261 different disaster areas of the Lushan earthquake. Chinese $J$ Emerg Recover Disaster Med 2014;9:105-7.

$7 \mathrm{Hu} \mathrm{H}, \mathrm{He} \mathrm{Y}$, Zhang S, et al. Streamlined focused assessment with sonography for mass casualty prehospital triage of blunt torso trauma patients. Am J Emerg Med 2014;32:803-6.

8 Pan S-T, Cheng Y-Y, Wu C-L, et al. Association of injury pattern and entrapment location inside damaged buildings in the 2016 Taiwan earthquake. J Formos Med Assoc 2019;118:311-23.

9 Cross KP, Cicero MX. Head-to-head comparison of disaster triage methods in pediatric, adult, and geriatric patients. Ann Emerg Med 2013;61:668-76.

10 Culley JM, Svendsen E. A review of the literature on the validity of mass casualty triage systems with a focus on chemical exposures. Am J Disaster Med 2014;9:137-50.

11 Imhoff BF, Thompson NJ, Hastings MA, et al. Rapid emergency medicine score (REMS) in the trauma population: a retrospective study. BMJ Open 2014;4:e004738-6.
12 Ruangsomboon O, Boonmee P, Limsuwat C, et al. The utility of the rapid emergency medicine score (REMS) compared with SIRS, qSOFA and news for predicting in-hospital mortality among patients with suspicion of sepsis in an emergency department. BMC Emerg Med 2021;21:1-13.

13 Cassignol A, Markarian T, Cotte J, et al. Evaluation and comparison of different prehospital triage scores of trauma patients on in-hospital mortality. Prehosp Emerg Care 2019;23:543-50.

14 Bazyar J, Farrokhi M, Khankeh H. Triage systems in mass casualty incidents and disasters: a review study with a worldwide approach. Open Access Maced J Med Sci 2019;7:482-94.

15 MacLeod JBA, Kobusingye O, Frost C, et al. A comparison of the Kampala trauma score (KTS) with the revised trauma score (Rts), injury severity score (ISS) and the TRISS method in a Ugandan trauma registry. European Journal of Trauma 2003;29:392-8.

16 Lin Y-K, Niu K-Y, Seak C-J, et al. Comparison between simple triage and rapid treatment and Taiwan triage and acuity scale for the emergency department triage of victims following an earthquakerelated mass casualty incident: a retrospective cohort study. World $\mathrm{J}$ Emerg Surg 2020;15:1-8.

17 Abajas-Bustillo R, Amo-Setién FJ, Leal-Costa C, et al. Comparison of injury severity scores (ISS) obtained by manual coding versus "Twostep conversion" from ICD-9-CM. PLoS One 2019;14:e0216206-12.

18 Elkbuli A, Yaras R, Elghoroury A, et al. Comorbidities in trauma injury severity scoring system: refining current trauma scoring system. Am Surg 2019;85:59-63.

19 Nasr A, Alsaeed F, Al-Safwani Z. Polytrauma patients between severity and intervention: what truly predicts outcome. Int J Med Dev Ctries 2020;4:809-14.

20 Lasota D, Goniewicz M, Kosson D, et al. Effects of ethyl alcohol on injuries severity according to injury severity scales in pedestrian fatal injury in traffic crashes. Int J Inj Contr Saf Promot 2020;27:112-20.

21 Toida C, Muguruma T, Abe T, et al. Introduction of pediatric physiological and anatomical triage score in mass-casualty incident. Prehosp Disaster Med 2018;33:147-52.

22 Zhang Y, Lin Q, Liu Y. The quick assessment model of casualties for Asia based on the vulnerability of earthquake. Nat Hazards Earth Syst Sci Discuss 2018:1-22.

23 Spence R, So E. Estimating shaking-induced casualties and building damage for global earthquake events, 2009. Available: http:// earthquake.usgs.gov/research/external/reports/08HQGR0102.pdf

24 Hong C, Efferth T. Systematic review on post-traumatic stress disorder among survivors of the Wenchuan earthquake. Trauma Violence Abuse 2016;17:542-61.

25 Rivas M, Luna P, Lizarazo-Marriaga J. Analytical fragility assessment of structures under earthquake and tsunami loads: a case study on the Colombian Pacific coast. TECNIA 2019;29:169-73.

26 Ping $\mathrm{H}$. Study of assessment method based on coupling factor of casualty in earthquake disasters in Guangdong area. Comput Syst Sci Eng 2020;35:191-9.

27 Gottschalk SB, Wood D, DeVries S, et al. The Cape triage score: a new triage system South Africa. proposal from the Cape triage group. Emerg Med J 2006;23:149-53.

28 Lichtveld RA, Spijkers ATE, Hoogendoorn JM, et al. Triage revised trauma score change between first assessment and arrival at the hospital to predict mortality. Int J Emerg Med 2008;1:21-6.

29 Yan B, Hai H, Yu C. The application value of three on-site inspection classification methods in the Lushan earthquake. Chinese J Emerg Res Dis Med 2015;6:541-5.

30 Nolan $\mathrm{B}$, Tien $\mathrm{H}$, Haas $\mathrm{B}$, et al. The rapid emergency medicine score: a critical appraisal of its measurement properties and applicability to the air retrieval environment. Air Med J 2019;38:154-60.

$31 \mathrm{He} \mathrm{Y,} \mathrm{Hu} \mathrm{H}$, Jiang Y. Comparison of the performance of three prehospital trauma scores in evaluationof injury severity among Lushan earthquake victims. Zhonghua Wei Zhong Bing JiJiu Yi Xue 2014;26:581-4. 